5 Nielsen J, Hreidarsson AB, Berggreen S, Reid E, Tsuboi T, Saldaña-Garcia $P$. A mentally retarded male with karyotype $47, \mathrm{XY}, \mathrm{mar}=? \mathrm{i}(18 \mathrm{p})$. Ann Genet (Paris) 1974;17:129-33.

6 Taylor KM, Wolfinger HL, Brown MG, Chadwick DL. Origin of a small metacentric chromosome: familial and cytogenetic evidence. Clin Genet 1975;8:364-9.

7 Balicek P, Zizka J, Lichý J. An isochromosome of the short arms of the no 18 chromosome in a mentally retarded girl. Clin Genet 1976;9:192-6.

${ }^{8}$ Ogata K, Iinuma K, Kamimura K, Morinaga R, Kato J. A case report of a presumptive $\mathrm{i}(18 \mathrm{p})$ associated with serum IgA deficiency. Clin Genet 1977;11:184-8.

9 Nielsen KB, Dyggve H, Friedrich U, Hobolth $\mathrm{N}$, Lyngbye T, Mikkelsen M. Small metacentric nonsatellited extra chromosome. Hum Genet 1978;44:59-69.

10 Rocchi M, Stormi M, Archidiacono N, Filippi G. Extra small metacentric chromosome identified as $\mathrm{i}(18 \mathrm{p})$. J Med Genet 1979;16:69-73.

Requests for reprints to Dr A M Vianna-Morgante, Departamento de Biologia, Instituto de Biociências USP, CP 11461, 05421 São Paulo, SP, Brazil.

\section{Distal monosomy 14 not associated with ring formation}

SUMMARY A 12-year-old boy with congenital heart disease, short stature, mildly dysmorphic facies, and mild intellectual impairment was found to have a de novo terminal deletion (14)(q32.3). Although his phenotype resembles that of six reported patients with a similar breakpoint, his CNS involvement is milder. He appears to be the first reported case of a terminal deletion of chromosome 14 not associated with ring 14 formation. Advanced parental ages and maternal origin of the chromosome with the deletion are noted.

Received for publication 20 September 1982.

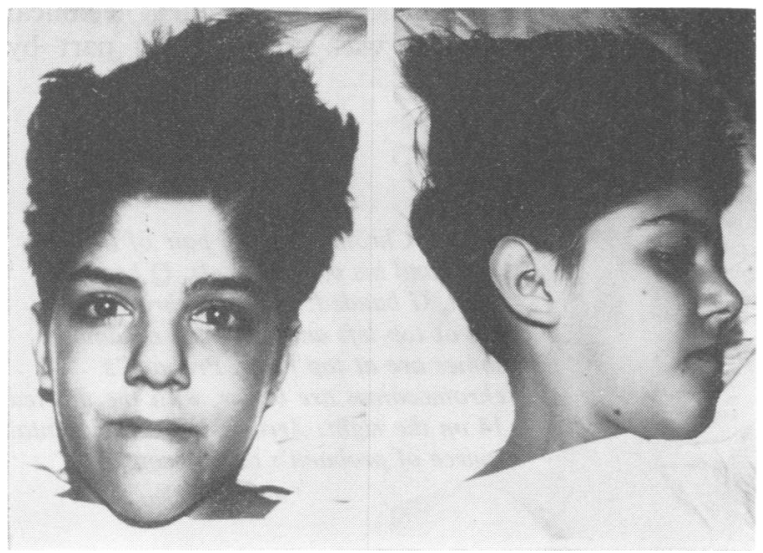

There are ten previously reported cases of termina! monosomy of chromosome $14 \mathrm{q}$ not associated with partial duplication of another chromosome. In nine, the loss was associated with ring formation, ${ }^{1-5}$ and in one ${ }^{6}$ with mosaicism for a complex inversion. We report the first case where the loss was the result of a simple de novo deletion.

\section{Case report}

The patient was a 12-year-old white male admitted for evaluation of congenital heart disease. He was born at term to 35-year-old unrelated parents, after an uncomplicated pregnancy, with a birth weight of $3250 \mathrm{~g}$. Except for the heart disease, he has remained in good physical health. A heart murmur was first detected when he was 2 years old and was followed with annual examinations. The present admission was prompted by decreasing exercise tolerance of 2 years' duration. Cardiac catheterisation showed an atrial septal defect and a partial anomalous venous return that have now been surgically corrected. His psychomotor development was delayed in comparison to his older sibs. In school he is two grade levels behind chronological age. Formal psychometric testing (WISC-R) showed low average intelligence (full scale IQ 85), but with significant verbal-performance discrepancy (verbal IQ 94, performance 78). There is no history of seizures or other neurological symptoms and an EEG was not performed. There is no family history of consanguinity, congenital malformations, or mental retardation. Both parents, an older brother, and three older sisters are in good health, of average height, and at least average intelligence.

On physical examination, the patient was a mildly dysmorphic child (fig 1). Weight was at the 5th centile and head circumference at the 50th centile, while the height was below the 3rd centile and at the
FIG 1 The proband at 12 years. Note high forehead, low anterior hairlire, broad nasal bridge, broad philtrum, and simple helix. 
50th centile for a 9-year-old. The dysmorphic features included a high forehead with a low anterior hairline; high arched palate with a marked maxillary overbite giving the appearance of micrognathia; a broad nasal bridge; broad philtrum; normally set ears, but with poor helix formation; and increased carrying angle of the elbows. Eye examination was normal with no ptosis present. The chest was without deformities, with normally spaced nipples. No organomegaly was present. The genitals were normal, with Tanner stage II sexual development. Neurological examination was normal, including muscle tone and tendon reflexes.

Chromosome analysis using $\mathbf{G}$ and $\mathbf{R}$ banding

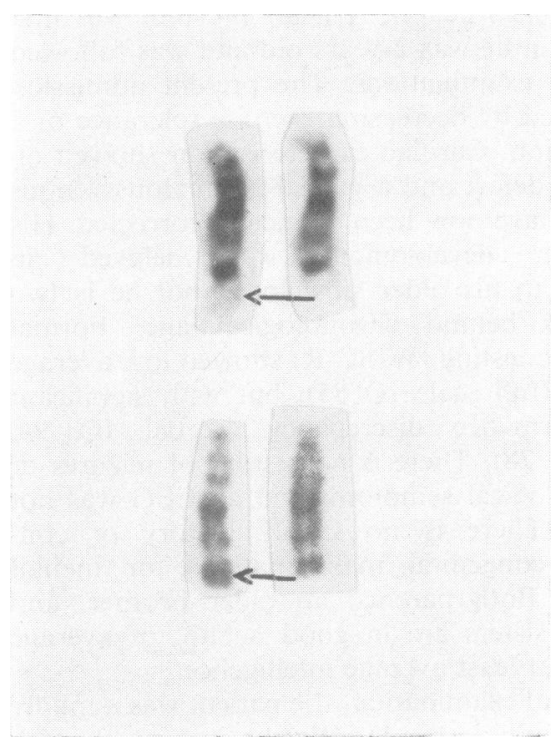

FIG 2 Chromosome 14 pair from two cells of the proband. Top cell, $G$ banded; bottom cell, $R B A$ banded. Left chromosome of each pair is the normal 14, the right is the deleted 14. Arrow indicates breakpoint at $14 q 32 \cdot 3$. techniques showed the breakpoint to be $14 \mathrm{q} 32 \cdot 3 \stackrel{\mathbb{D}}{\overparen{D}}$ (fig 2). Six of the ten previous cases have also had a $\stackrel{+}{?}$ breakpoint within band 14q32. Banded karyotypes $\overrightarrow{\overrightarrow{\vec{S}}}$ of both parents were normal. Satellite polymorphisms using $\mathrm{G}$ and $\mathrm{Q}$ banding showed the deleted chromosome 14 to be maternal in origin $\frac{O}{\mathrm{c}}$ (fig 3).

\section{Discussion}

Our patient shows many of the dysmorphic features? shown by the six cases which share a similar break- $\vec{\omega}$

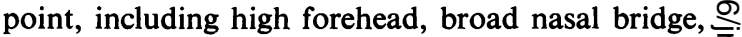
high arched palate, ear abnormalities, and short stature. He has milder CNS involvement; the is absence of seizures is of note because they are considered a consistent feature of ring $14 \stackrel{-}{-}$ syndrome. ${ }^{13}$ His intellectual status, although clearly lower than that of other family members, is in the 음 normal range. Head size and muscle tone are normal. The most severe finding in our patient, congenital $\rightarrow$ heart disease, was present in only two of the other six cases; both of these had pulmonary stenosis.

An interesting cytogenetic observation is the preponderance of rings among previously reported cases with terminal deletions of chromosome 14 . The same is true for chromosome $13 .^{7}$ This may reflect over-reporting of ring chromosomes or under-detection of simple, small, terminal deletions, which are difficult to visualise in comparison to rings.

The mean maternal age at birth of a child with $14 \mathrm{q}-$ in the nine cases (ours included) where data were available is 28.2 years, about 2 years higher than expected. ${ }^{8}$ Advanced maternal age may therefore be a factor in the occurrence of de novo deletions. It would be useful if studies of such cases $\dot{0}$ would, in the future, include determination of the parental origin of the deletion.

We thank Barbara Jackson for excellent technical 우 assistance. This work was supported in part by

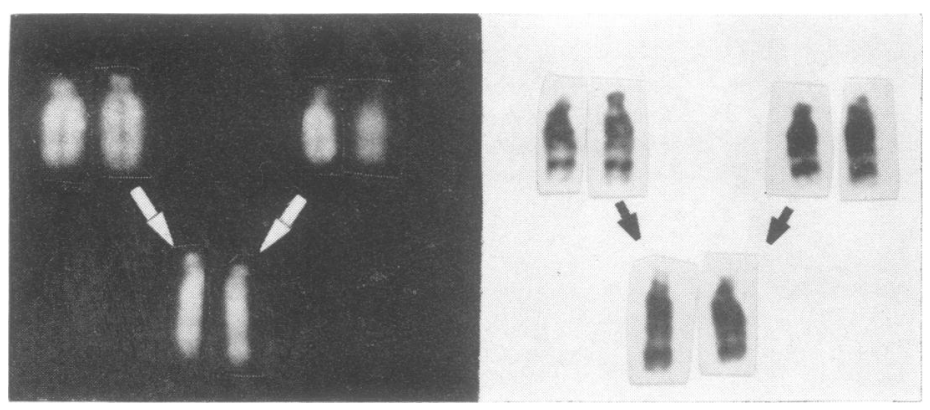

FIG 3 Chromosome 14 pair of the proband and his parents. Left, $Q$ banded; right, $G$ banded. Paternal chromosomes are at top left and maternal chromosomes are at top right. Proband's chromosomes are below, with the deleted 0 14 on the right. Arrows indicate parental source of proband's chromosomes. 
Grant No 917, Maternal and Child Health, Department of Health and Human Services.

\section{Stefan J Hreidarsson and Judith Stamberg} The John F Kennedy Institute and the Department of Pediatrics, Johns Hopkins School of Medicine, Baltimore, Maryland, USA.

\section{References}

1 Schmidt R, Eviatar L, Nitowsky HM. Wong M, Miranda S. Ring chromosome 14: a distinct clinical entity. J Med Genet 1981;18:304-7.

2 Vekemans M, Watters G, Tsipouras P, Bourrouilh $\mathbf{H}$. Ring 14 chromosome identified by banding techniques. Am J Hum Genet 1979;31:115A.

${ }^{3}$ Lippe BM, Sparkes RS. Ring 14 chromosome: association with seizures. Am J Med Genet 1981;9:301-5.

4 Triolo O, Serra A, Bova R, Carlo Stella N, Caruso P.
Infant male with ring chromosome 14. Ann Genet (Paris) $1981 ; 24: 236-8$.

5 Riley SB, Buckton KE, Ratcliffe SG, Syme J. Inheritance of a ring 14 chromosome. J Med Genet $1981 ; 18: 209-13$.

6 Nielsen J, Homma A, Rasmussen K, Ried E, Sørensen K, Saldaña-Garcia $P$. Deletion $14 \mathrm{q}$ and pericentric inversion 14. J Med Genet 1978;15:236-8.

$?$ Niebuhr E. Partial trisomies and deletions of chromosome 13. In: Yunis JJ, ed. New chromosomal syndromes. New York: Academic Press, 1977:273-99.

8 Hook EB, Chambers GM. Estimated rates of Down syndrome in live births by one year maternal age intervals for mothers aged 20-49 in a New York State studyimplications of the risk figures for genetic counselling and cost-benefit analysis of prenatal diagnosis programs. Birth Defects 1977;XIII, No 3A:123-41.

Requests for reprints to Dr Judith Stamberg, Genetics Department, John F Kennedy Institute, 707 N Broadway, Baltimore, Maryland 21205, USA. 